\title{
Production of high-purity ethyl acetate using reactive distillation: Experimental and start-up procedure
}

\author{
I-Kuan Lai ${ }^{\text {a }}$, Yan-Chun Liu ${ }^{b}$, Cheng-Ching $\mathrm{Yu}^{\mathrm{a}}$, \\ Ming-Jer Lee ${ }^{\mathrm{c}}$, Hsiao-Ping Huang ${ }^{\mathrm{a}, *}$ \\ a Department of Chemical Engineering, National Taiwan University, Taipei 106-17, Taiwan \\ ${ }^{\mathrm{b}}$ Industrial Technology Research Institute, Hsin Chu 310, Taiwan \\ ${ }^{\mathrm{c}}$ Department of Chemical Enginering, National Taiwan University of Science and Technology, Taipei 106, Taiwan
}

Received 23 May 2007; received in revised form 28 September 2007; accepted 7 October 2007

Available online 13 October 2007

\begin{abstract}
The production of high-purity ethyl acetate (EtAc) using reactive distillation (RD) is studied experimentally in a pilot-scale plant. The objectives are twofolds: (1) to realize the type-II RD process [Y.T. Tang, Y.W. Chen, H.P. Huang, C.C. Yu, S.B. Huang, M.J. Lee, Design of reactive distillations for acetic acid esterification with different alcohols, AIChE J. 51 (2005) 1683-1699] for EtAc production with a pilot plant, a complex two-column configuration with liquid phase split, (2) to study the initial charges to the column holdups and a start-up procedure for continuous production. This pilot-scale plant consists of one RD column (10 reactive trays plus structured packing for separation) and a downstream stripper with a decanter in between. The two columns are equipped with temperature, flow, and level measurements and a Delta-V process control computer. The industrial grade alcohol $\left(89 \mathrm{~mol} \% \mathrm{EtOH}, 11 \mathrm{~mol} \% \mathrm{H}_{2} \mathrm{O}\right)$ and acid $\left(96.75 \mathrm{~mol} \% \mathrm{HAc}\right.$ and $\left.3.25 \mathrm{~mol}_{\%} \mathrm{H}_{2} \mathrm{O}\right)$ are used as reactants. A product that contains more than $99 \mathrm{~mol} \% \mathrm{EtAc}$ and less than $100 \mathrm{ppm}$ HAc is required as specifications. The results from six experimental runs show that, with proper initial charges in the inventory holdups and a systematic start-up procedure, high-purity acetate can be produced in a straightforward manner.
\end{abstract}

(C) 2007 Elsevier B.V. All rights reserved.

Keywords: Ethyl acetate; Reactive distillation; Start-up; Pilot plant test; Esterification

\section{Introduction}

Ethyl acetate (EtAc) is an important organic solvent widely used in the chemical industry. One of the key issues in the production of acetates is the equilibrium limitation from the reversible reaction of acetic acid and alcohols. This motivates the use of reactive distillation (RD) to achieve high conversion. The reactive distillation is featured with its merits not only in promoting the reaction conversion, but also in reducing both the capital and operational costs as its multifunctional nature. The RD process appeared first in 1932 [2] for the production of EtAc and became a new focus in 1980's, since Eastman Chemical Company owned a commercial reactive distillation process for the production of methyl acetate. Later on, extensive researches on the RD process appeared in the literature. At the

\footnotetext{
* Corresponding author. Tel.: +886 22363 8999; fax: +88622362 3935 .

E-mail address: huanghpc@ntu.edu.tw (H.-P. Huang).
}

same time, successful commercial processes that apply reactive distillation are installed for producing various chemicals such as methyl tert-butyl ether (MTBE), cumene, ethyl-benzene, and 3-methyl-1-butene, etc.

Conceptually, a RD column has three basic elements: rectifying section on the top, reactive section in the middle, and the stripping section at the bottoms. Keyes [2] was among the first who studied a reactive distillation process for the production of ethyl acetate (EtAc) using a pre-reactor, two recovery columns, and one decanter. Later, design for EtAc process that involves the use of $\mathrm{RD}$ reported in the literature has wide varieties. Table 1 shows some of such works that have experiments. Wu and Lin [3] proposed a multi-unit system (see Table 1A), which consists of one fixed-bed and a catalytic RD column with a decanter. Kenig et al. [4] studied a process that has one single column with 80 bubble cup trays (see Table 1B). Klöker et al. [5] used two RD columns of different sizes (Table 1C), and, Reepmeyer et al. [6] (Table 1D) and Kolena et al. [7] (Table 1E) studied also one single-column systems. Many of the above-mentioned 
Table 1

Literature EtAc experimental setups and corresponding purity levels

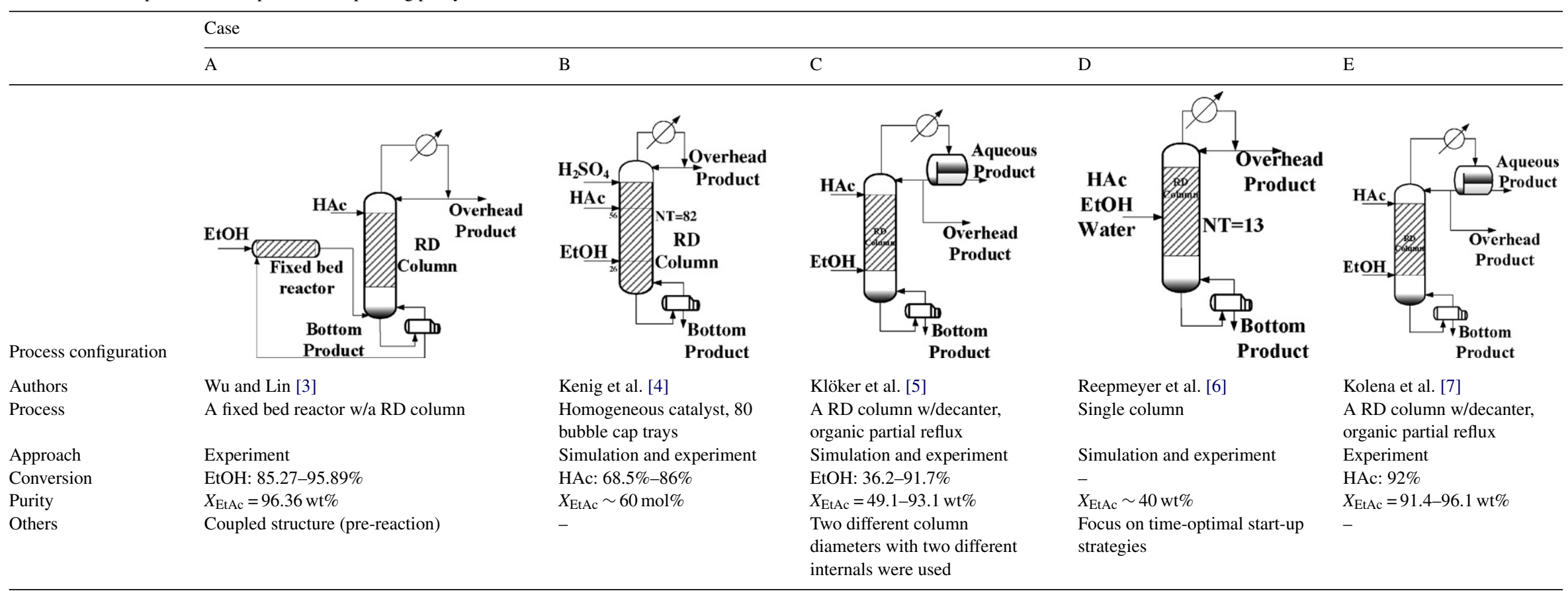


Table 2

Temperatures and compositions of azeotropes for EtAc system (1 atm)

\begin{tabular}{lll}
\hline Comp. $i$ & $\begin{array}{l}\text { Experimental } \\
\text { components }\end{array}$ & $\begin{array}{l}\text { Experimental } \\
\text { temperature } \\
\left({ }^{\circ} \mathrm{C}\right)\end{array}$ \\
\hline $\mathrm{EtOH} / \mathrm{EtAc}$ & $(0.462,0.538)$ & 71.81 \\
$\mathrm{EtOH} / \mathrm{H}_{2} \mathrm{O}$ & $(0.9037,0.0963)$ & 78.174 \\
$\mathrm{EtAc} / \mathrm{H}_{2} \mathrm{O}$ & $(0.6885,0.3115)$ & 70.38 \\
$\mathrm{EtOH} / \mathrm{EtAc} / \mathrm{H}_{2} \mathrm{O}$ & $(0.1126,0.5789,0.3085)$ & 70.23 \\
\hline
\end{tabular}

works mostly focuses on developing mathematical models with the experimental fitting. They did not focus on designing for achieving high conversion. For this, in general, those reported processes have low chemical conversion in the RD column and the low EtAc concentration in the product. Until lately, Tang et al. [1] presented a type-II process from their esterification of $\mathrm{C} 1-\mathrm{C} 5$ alcohols with HAc acid. This type-II process uses a decanter to remove water and a different configuration for $\mathrm{RD}$ column, which is very different from those in other EtAc processes. It has obvious advantages over the other designs on the aspects of high purity of EtAc product, stringent limitation on HAc impurity, and high chemical conversion (almost 100\%). The objectives of this work are to realize this new reactive distillation process with a pilot plant, and explore the procedures that could consistently lead to an efficient and economical production of EtAc.

The remainder of this paper is organized as the follows. First, the physical properties and process characteristics are investigated. Next, experimental setup and the conceptual design are described. Then, different start-up runs are explored followed by the conclusion.

\section{Process descriptions}

In the EtAc system, the mixtures exhibit non-ideal phase behaviors. There are three binary minimum-boiling azetropes and one ternary minimum-boiling azeotrope in the system. The temperatures and the compositions of these azeotropes are given in Table 2. It should be noted here that, in this system, the ternary minimum-boiling azeotrope consists of EtOH, EtAc and water. Fig. 1 shows the RCM diagrams of this EtAc-EtOH- $\mathrm{H}_{2} \mathrm{O}$ system. In this diagram, significant two-liquid (LL) phase envelope is observed. The ternary minimum-boiling azeotrope lies closely to the boundary of LL envelope. It is interesting to see that, in EtAc system, the tie lines slop toward pure water node and, consequently, relatively pure water can be recovered from the LL separation. This implies that a decanter is desirable to remove water.

The alcohol studied in this work is ethanol (EtOH), and corresponding products is ethyl acetate (EtAc). The reversible reaction can be expressed as

$\mathrm{EtOH}+\mathrm{HAc} \underset{k_{-1}}{\stackrel{k_{1}}{\rightleftarrows}} \mathrm{EtAc}+\mathrm{H}_{2} \mathrm{O}$

This is a solid acid catalyzed reaction with acidic ionexchange resin (Amberlyst 35 wet; Rohm and Hass). An important feature in the EtAc system is that it has a LL envelope

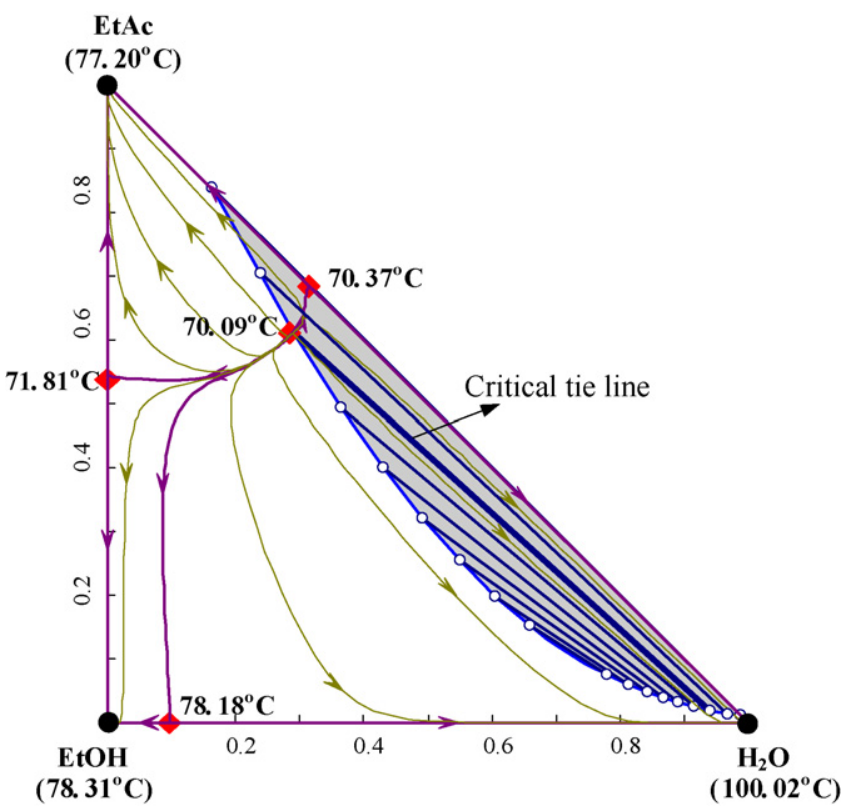

Fig. 1. The RCM diagram of EtOH-EtAc- $\mathrm{H}_{2} \mathrm{O}$ system and two-liquid zone with corresponding tie lines where the critical tie line indicating the limit that organic phase falling into different distillation boundaries.

with tie lines points toward the water-rich corner. In the design of Tang et al. [1], the reactive zone extends to the column base and a reboiler with larger holdup in the first column (later on, it will be referred as RD column). This is advantageous from reaction perspective, because the high temperature in the reboiler favors the forward side of reaction. In this work, the column base holdup is taken as 10 times of the tray holdup in the column. Despite this, about $20 \%$ of reaction takes place in the column (Lai et al. [9]). Without this portion of reaction in the RD column, high conversion would not achievable. The reactive section consumes up almost all the acid and reaches, through the rectifying section, a composition very close to the ternary minimum azeotrope. On the top of this RD column, the composition of the heavy acid (HAc) is reduced to a ppm level. The acid impurity in the product is very stringent and is dependent on the amount of acid allowed in the overhead of the RD column. The overhead composition of the RD column approaches the ternary azetrope composition from an alcohol lean side (see RCMs in Fig. 1). A decanter is placed on the top for water removal. Part of the organic phase

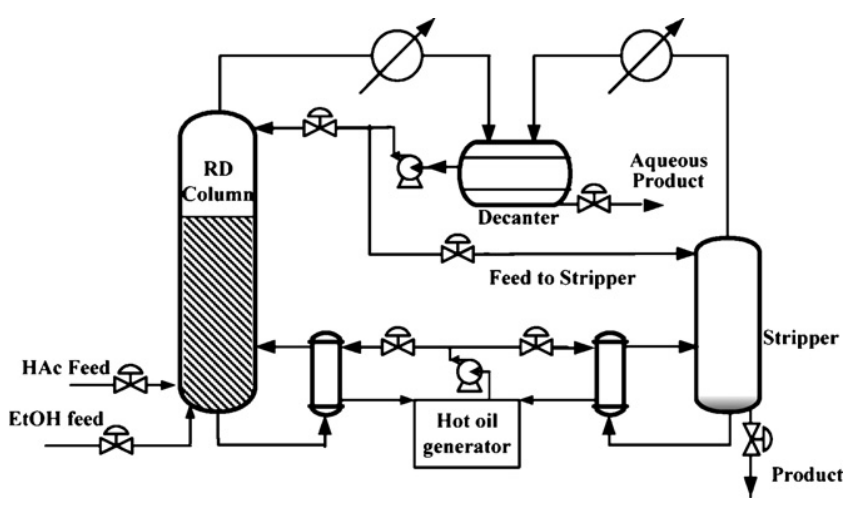

Fig. 2. Process flowsheet of EtAc system. 


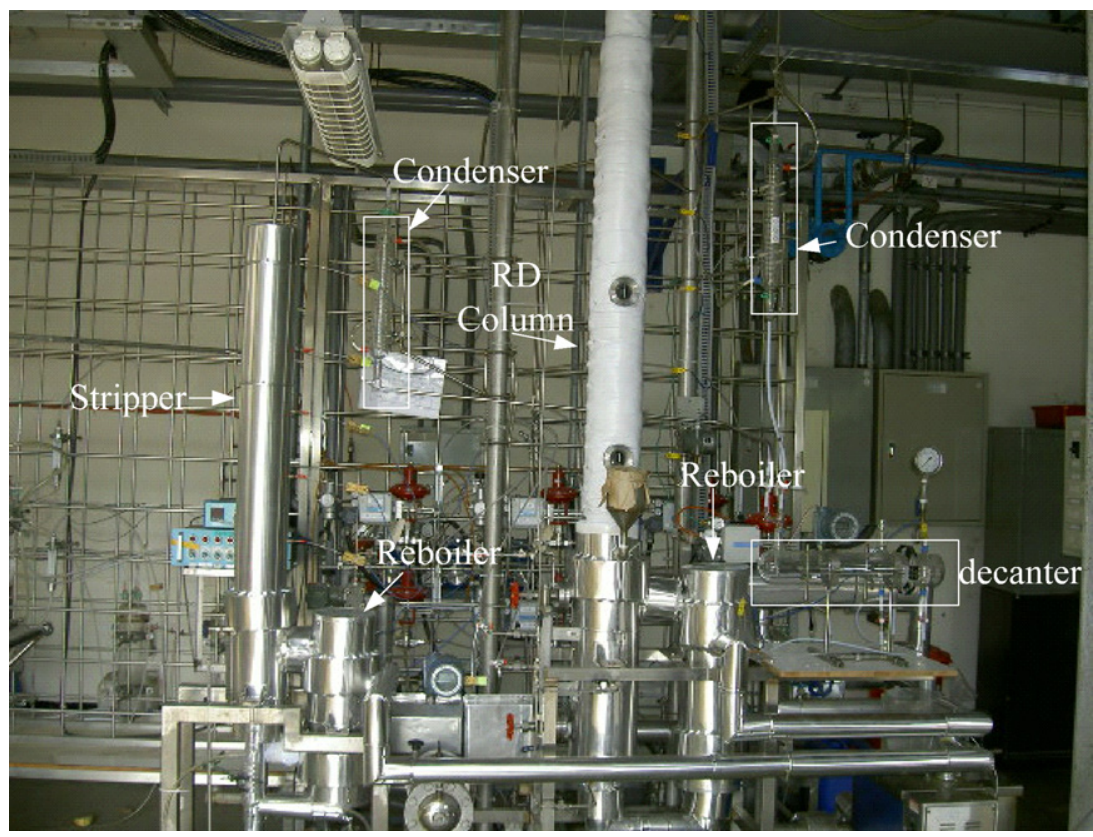

Fig. 3. The experimental setup of reactive distillation system.

is recycled back to the RD column, and, the remaining is fed to a stripper in the down stream for further purification. The top condensate, which contains unused reactants, from the top of stripper is recycled back to the decanter. In this study, the feed composition of alcohol is $95.5 \mathrm{wt} \%(89 \mathrm{~mol} \%)$, and industrial grade acetic acid of $99 \mathrm{wt} \%(96.75 \mathrm{~mol} \%)$ with water as impurity is used. The flowsheet of this conceptual design is as shown in Fig. 2. Steady-state simulations via the Aspen Plus show that this process yields high purity of EtAc as the products in the bottom of the stripper (the upper corner distillation region in Fig. 1).

\section{Experimental}

The experimental setup is given in Fig. 3. The setup includes a RD column in the middle, a stripper to the left, and a decanter on the lower right-hand side. It was constructed with $316 \mathrm{~L}$ stainless steel. The rectifying section of the RD column and the stripper, each has a diameter of $55 \mathrm{~mm}$ and is packed with structured packing. A special type of device, which is known as Jet Coflow Packing Trays (JCPT; Fig. 4), is used for the reactive tray. For each reactive tray, two solid catalyst packings (Fig. 4B) are placed around the inner annular tube as shown in Fig. 4C. Fig. 4A shows the internal construction of this reactive tray. In each tray, vapor goes up along the annular tube in the middle and has direct contact with the liquid from above through the slit opening. The vapor is not in direct contact with the catalyst. The liquid flows over through the eccentric tube to the distributor on the next tray and contact the catalyst. Each tray contains $88 \mathrm{~g}$ wet Amberlyst 35 catalyst. In the RD column base, it is filled with $880 \mathrm{~g}$ catalyst, 10 times to the catalyst in each tray. The rectifying section in the RD (Fig. 5A) and the stripper are filled with random packing (Fig. 5B). For measuring the temperature profiles in the two columns, thermocouples are installed on the stripper and the RD column. In the stripper, the thermocouples are enumerated from top to bottom and are labeled with TI101 to 106. Similarly, in the RD column, the thermocouples are numbered from top to bottom in the rectifying section (TI-201 to 207) as well as in the reactive zone (TI-208 to 213).

Another important device, the decanter, is used to separate aqueous phases from organic phase for water removal. The operation condition is under room temperature. The construction of the decanter is shown in Fig. 6. The U-tube can be moved vertically to adjust aqueous and organic levels. The organic phase in the decanter overflows over the weir in the decanter to a storage tank, whose level is controlled by manipulating the decanter outlet to the stripper. The reflux ratio (organic phase recycle flow/organic phase flow to stripper) is kept constant. The aqueous phase product $\left(\mathrm{H}_{2} \mathrm{O}\right)$ is withdrawn from the system, whose level is controlled using a U-tube device. The complete P\&ID is shown in Fig. 7. The reboilers in the RD and the stripper are heated with hot oil in a closed circulation system (Fig. 2). Pumped hot oil goes into the reboiler. After, it is recycled to the hot oil heater. The temperature of the heater is set to $180^{\circ} \mathrm{C}$. The distribution of the flows is flow controlled. The base level of stripper is maintained by a U-tube level controlling device, and the RD base level is controlled by the heat input ([8,9]).

For composition analysis, the liquid or condensed samples were taken from the column and/or decanter, and they are subsequently analyzed using gas chromatograph (GC).

\section{Start-up procedure and experimental results}

As shown in Fig. 2, the type-II RD process for EtAc production differs from others in the following aspects:

(1) No output from the RD column base.

(2) A decanter on the top of RD column for water removal. 
(A)

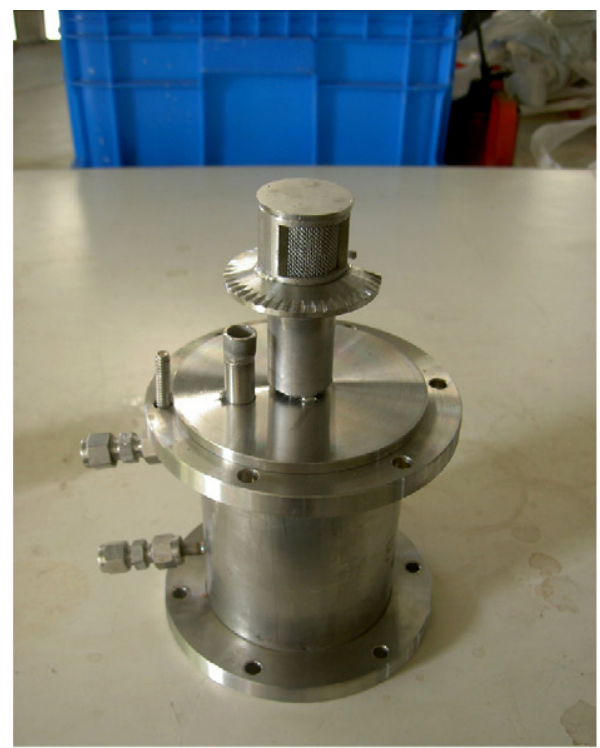

(B)

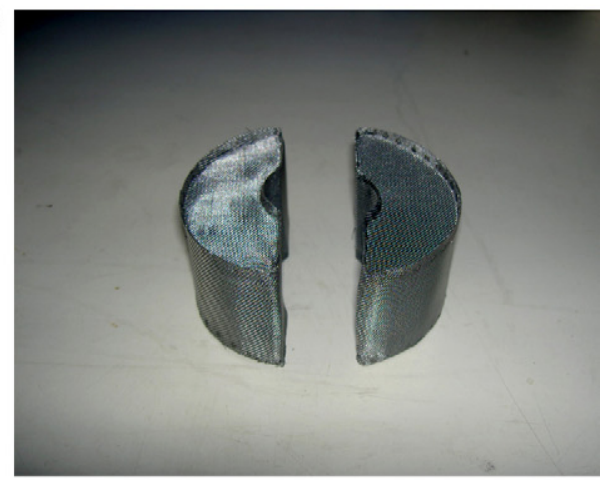

(C)

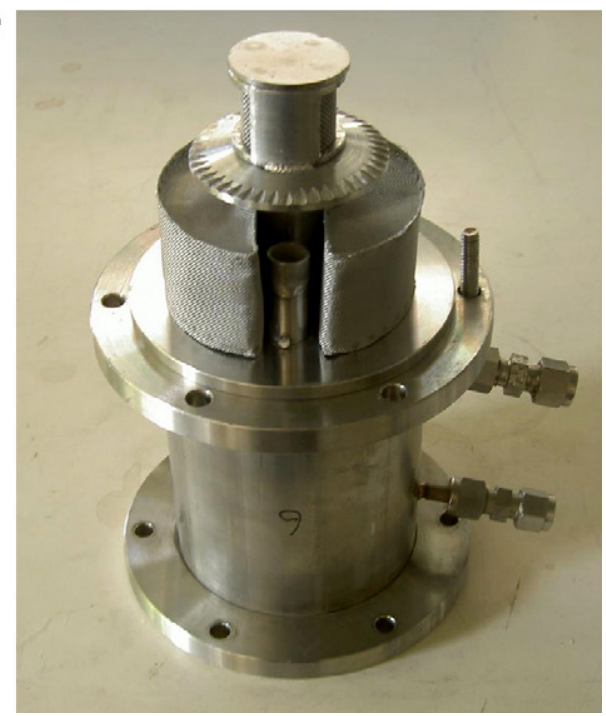

Fig. 4. (A) Jet Co-flow packing trays (JCPT) without catalyst, (B) catalyst packing, and $(\mathrm{C})$ completed reactive tray assembly.

(3) Constant ratio between the flows of organic reflux and the distillate to the stripper.

(4) A separate stripper section.

In order to have high purity of EtAc from the stripper bottom, the organic phase composition should cross the distillation
(A)

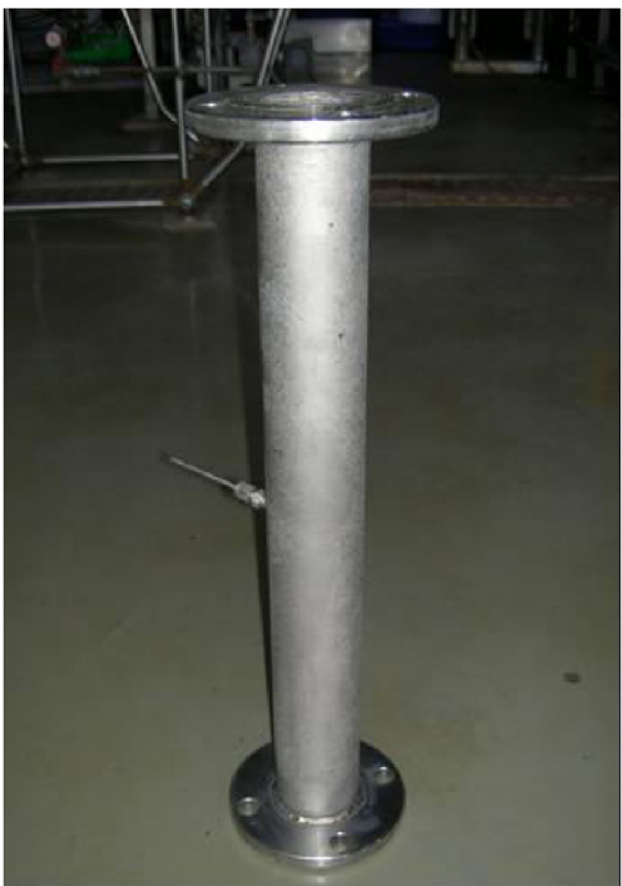

(B)

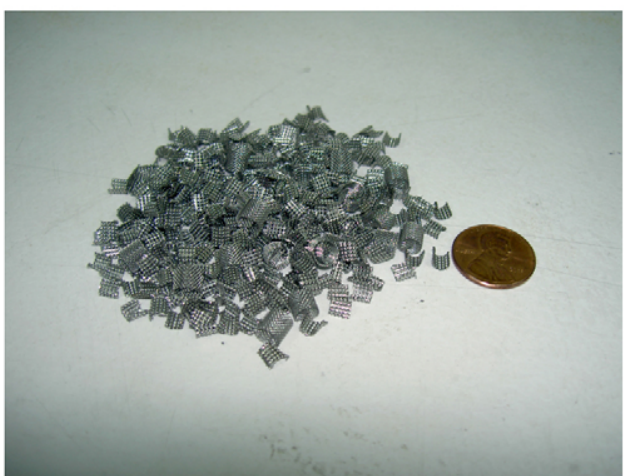

Fig. 5. (A) Packed rectifying section and stripper with thermocouple nozzles and $(\mathrm{B})$ random packing.

boundary and locates in the zone A of Fig. 11. In a successful run, this organic phase composition should be achieved since the very beginning of start-up. For this, necessary conditions for a successful run based on the conceptual design are concluded

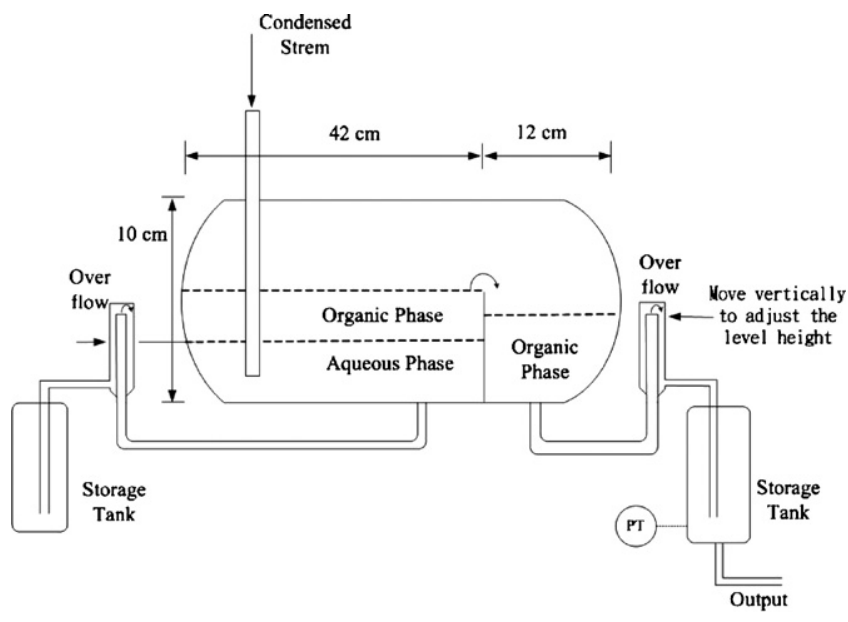

Fig. 6. Schematic of decanter and storage tank. 


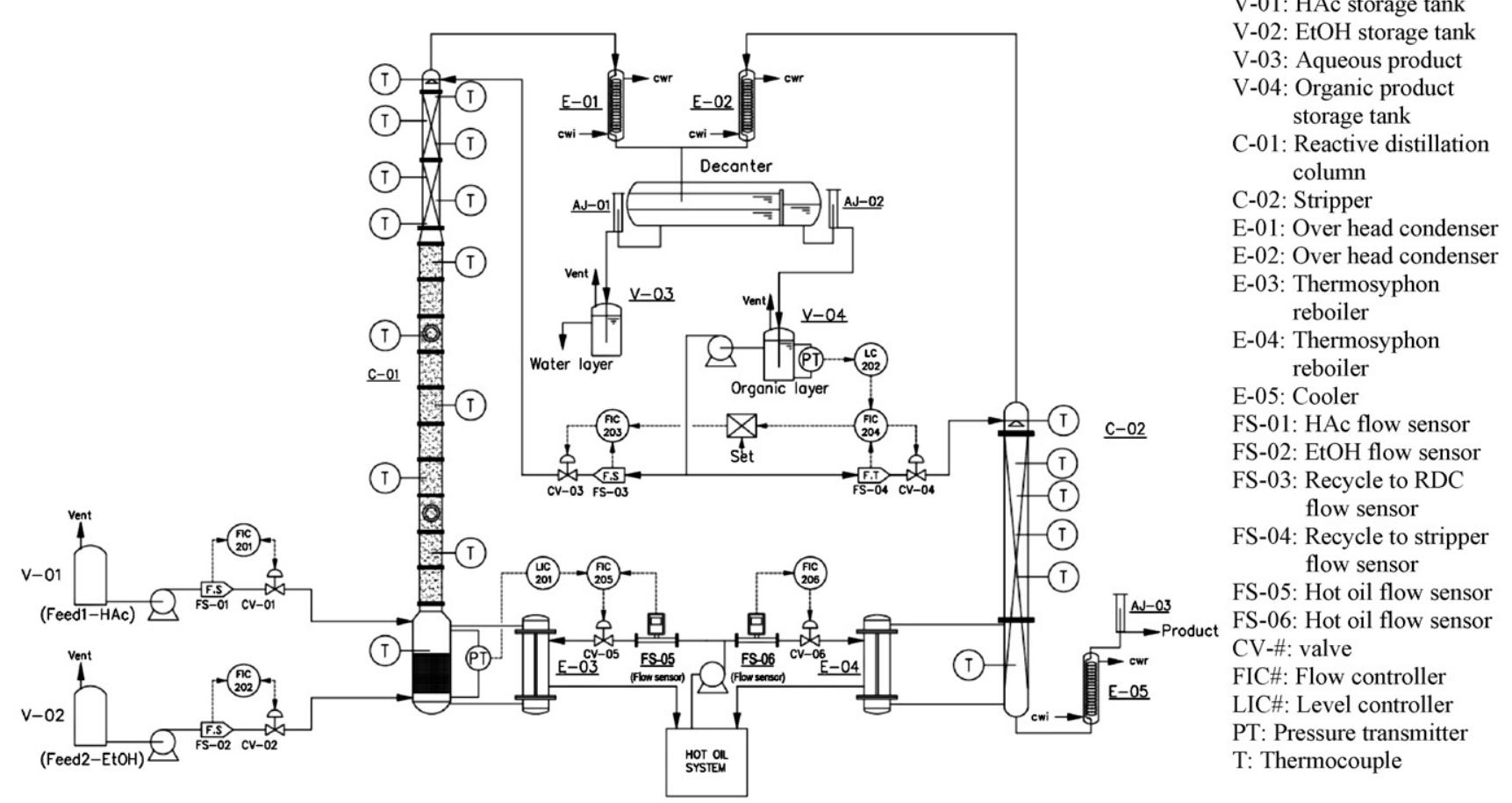

Fig. 7. Process and instrumentation diagram (P\&ID) of the entire type-2 reactive distillation system.

as follows:

1. The overhead vapor composition from the RD must lie in the two-liquid (LLE) zone and the liquid phases consist of a aqueous phase, rich of water, and the organic phase, rich in acetate.

2. The overhead vapor composition of the stripper must lie in the two-liquid (LLE) zone.

3. The organic phase composition should fall in the pure acetate corner of the composition space, as shown in Fig. 1, separated by a distillation boundary.

\subsection{Start-up procedure}

Several trials with different initial holdup charges in the columns are tried on this pilot plant. It is found that these initial charges in the holdups and the heating up procedure as well as some of the temperatures in specific parts of the columns are essential in this start-up operation. In general, during the start-up, liquid-liquid phase split and a feasible lumped composition in the decanter are important since the very beginning of start-up. For this, the decanter and the storage tank of the RD column, and the bottom of the stripper are charged initially with almost pure EtAc. Also, the base of RD column is charged with almost pure acid. In addition, the operating sequence to heat up the system is also important. The heatingup starts with the RD column from the base, the bottom of rectifying section, then the top. In the meantime, the stripper base and, finally, its top are heated up. Temperatures at the different part of RD column and the stripper during this startup period should be monitored at some specified values in a sequential manner, that is: first, the bottom of $\mathrm{RD}$ and rectifying section, then, the top of RD, and, finally, the stripper bottom. To maintain those temperatures mentioned, the heating utilities such as the heat duty to the reboilers must be adjusted.

According to the above-mentioned operation keys, a specific procedure that lead to reproducible high purity of EtAc in these trial runs and are described in the following:

1. Initial charges:

a. EtAc in the decanter (up to the weir height) and in the storage tank (up to $50 \%$ of level).

b. EtAc product in the bottom of the stripper (up to 50-75\% of level).

c. Acid feed in the RD column base up to $75 \%$ level.

2. Utility systems:

a. Turn on the hot oil system heater and the temperature is set to $180^{\circ} \mathrm{C}$.

b. Turn on the chilled water supply for the decanter and the temperature of chilled water is set to $10^{\circ} \mathrm{C}$.

3. Heating up and fresh feeding:

a. Heat up the RD column base by adjusting the hot oil flow rate manually (see Fig. 8A, S1). Once the bottoms temperature (TI-213) reaches $100-110^{\circ} \mathrm{C}$, start to feed the acid and alcohol to the RD column base (see Fig. 8A, S2). By this procedure, the RD column base level is maintained as the reaction proceeds.

b. The bottom of stripper is pre-heated gradually as steps 1-2 proceed (see Fig. 8B, S5).

c. When the temperature of bottom rectifying section (TI207) reaches $70-75^{\circ} \mathrm{C}$, change the hot oil flow rate such 


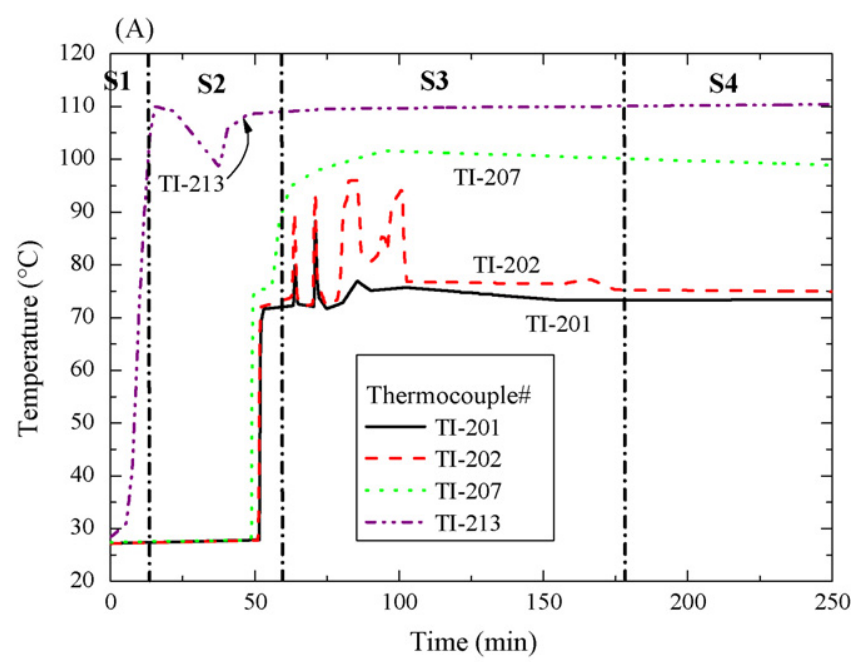

(B)

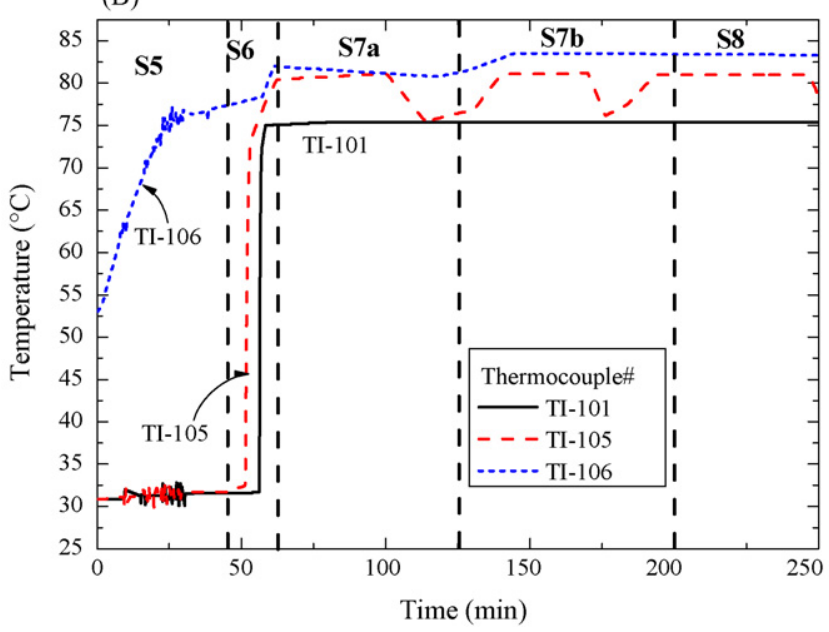

Fig. 8. The start-up temperature profile of Run 5 in (A) RD column and (B) stripper.

that the stripper bottoms temperature is kept around $80^{\circ} \mathrm{C}$ (see Fig. 8B, S6).

4. Reflux and heat-duty adjustment:

a. After the RD column top temperature (TI-201) reaches $72{ }^{\circ} \mathrm{C}$, open the reflux flow valve and send the organic phase flow to the stripper (see Fig. 9A and B, S2). Note that, at this moment, the RD column temperatures may exhibit certain degree of oscillation (see Fig. 8A, S3).

b. Adjust the reboiler duty of the RD column to maintain the level in the column base.

c. Manipulate heat input to the stripper to keep the bottom temperature of the stripper above $81^{\circ} \mathrm{C}$. The reason for that is the organic phase feed tends to lower the stripper temperature and the column base temperature should be maintained for product quality (see Fig. 8B, S7a).

5. Product withdrawal:

a. Open the aqueous product valve to withdraw the waterrich product when the aqueous phase in the decanter accumulated to a certain amount.

b. Put the level control of the organic storage thank level on automatic. During the transient, the temperatures in the stripper are subject to disturbances (see Fig. 8B, S7b and Fig. 9B, S3).

c. Withdraw EtAc product from the stripper when the stripper bottoms temperature becomes greater than $81^{\circ} \mathrm{C}$, or when significant base level has been built up.

6. Fine tune:

a. Adjust the RD reflux flow rate such that the RD top temperature (TI-201) is maintained in the range of $72-75^{\circ} \mathrm{C}$.

b. Manipulate the heat input to the stripper reboiler to maintain the bottoms temperature (TI-106) around $81-84^{\circ} \mathrm{C}$.

c. Three hours into the start-up, the system is reaching a steady state (see Fig. 8A and 9B, S4 and Fig. 8B, S8). At this stage, the control of the base level in the RD is switched to automatic. Also, the organic reflux flow back to the RD is controlled at a constant ratio to the flow rate to the striper.

7. Composition analysis:

a. Keep this steady-state for 2-3 h. During this period, samples from the RD column and stripper and from the organic/aqueous phase are collected for subsequent analysis.
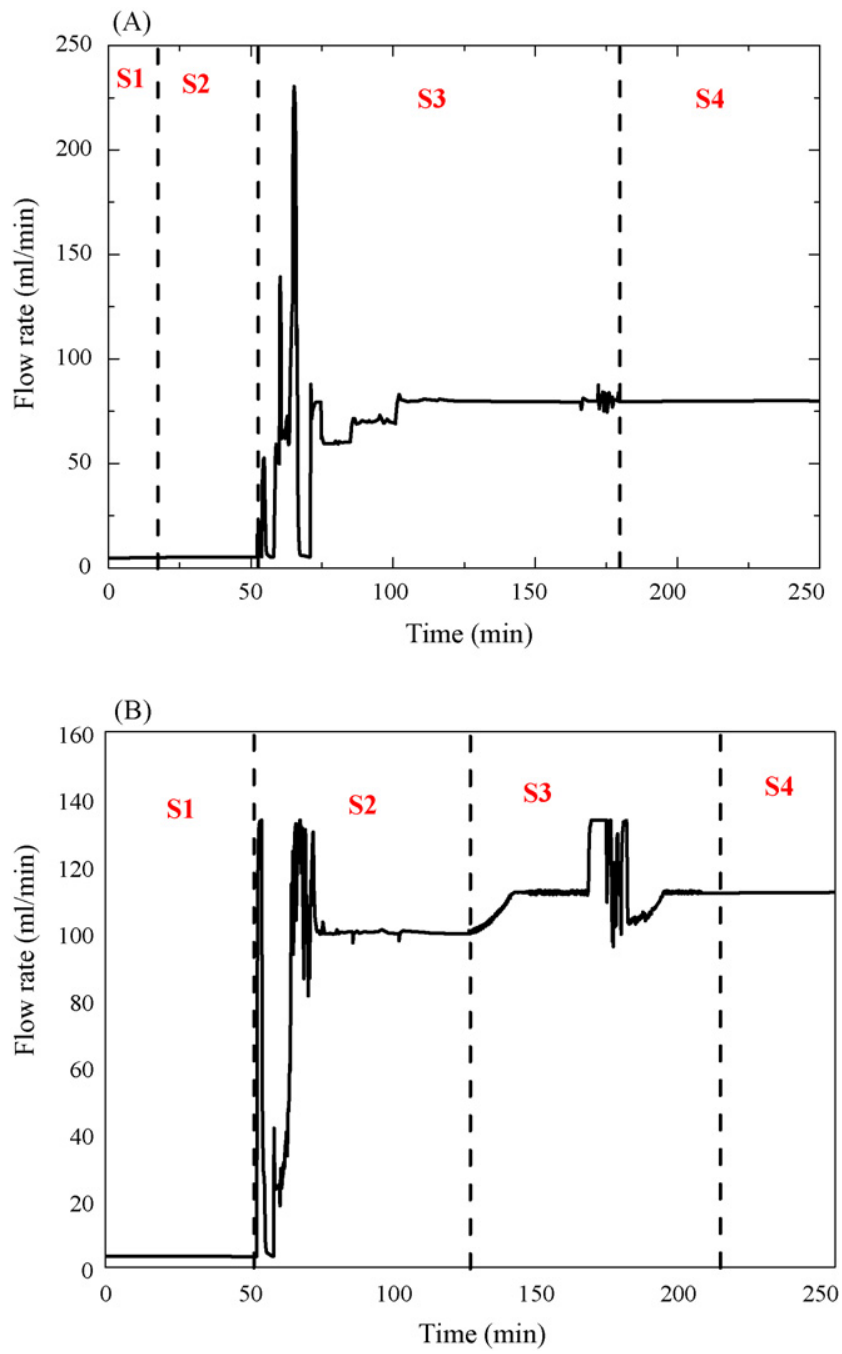

Fig. 9. For Run 5 (A) organic reflux flow rate of the RD column and (B) organic distillate flow rate (feed to the stripper). 
Table 3

Summary of six experimental start-up runs with feed condition, initial holdup composition, operating condition, and product purity

\begin{tabular}{|c|c|c|c|c|c|c|}
\hline & \multicolumn{6}{|l|}{ Run \# } \\
\hline & 1 & 2 & 3 & 4 & 5 & 6 \\
\hline Date & 24 February 2006 & 12 May 2006 & 22 May 2006 & 29 May 2006 & 12 June 2006 & 23 June 2006 \\
\hline \multicolumn{7}{|l|}{ Feed condition } \\
\hline$X_{\text {acid }}(\mathrm{mf})$ & 0.9675 & 0.9675 & 0.9675 & 0.9675 & 0.9675 & 0.9675 \\
\hline$X_{\mathrm{EtOH}}(\mathrm{mf})$ & 0.8698 & 0.8698 & 0.8698 & 0.8698 & 0.8698 & 0.8698 \\
\hline$F_{\text {acid }}(\mathrm{mol} / \mathrm{min})$ & 0.3641 & 0.1821 & 0.1821 & 0.2858 & 0.2858 & 0.2858 \\
\hline$F_{\mathrm{EtOH}}(\mathrm{mol} / \mathrm{min})$ & 0.4008 & 0.1961 & 0.1954 & 0.3067 & 0.3067 & 0.3067 \\
\hline Molar ratio (acid/EtOH) & 0.960 & 0.985 & 0.985 & 0.985 & 0.985 & 0.985 \\
\hline WHSV & 1.302 & 0.644 & 0.644 & 1.01 & 1.01 & 1.01 \\
\hline \multicolumn{7}{|l|}{ Initial holdup composition } \\
\hline RD Base $\left(V_{\text {acid }} / V_{\text {EtOH }}\right)$ & $5 / 1$ & $4 / 1$ & $\infty$ (pure acid) & $15 / 1$ & $\infty$ (pure acid) & $\infty$ (pure acid) \\
\hline Decanter $\left(V_{\mathrm{EtAc}} / V_{\text {water }}\right)$ & $2 / 1$ & $4 / 1$ & $\infty($ pure EtAc $)$ & $\infty($ pure EtAc) & $\infty$ (pure EtAc) & $\infty$ (pure EtAc) \\
\hline Stripper bottoms & N/A & (pure EtAc) & (pure EtAc) & (pure EtAc) & (pure EtAc) & (pure EtAc) \\
\hline \multicolumn{7}{|l|}{ Operation condition } \\
\hline Organic reflux (mol/min) & 1.4360 & 1.2721 & 1.5839 & 1.0617 & 1.0862 & 1.6289 \\
\hline Feed to stripper (mol/min) & 1.4360 & 0.7587 & 0.9123 & 0.6066 & 1.5207 & 1.5203 \\
\hline Reflux ratio & 1 & 1.68 & 1.73 & 1.75 & 0.71 & 1.07 \\
\hline \multicolumn{7}{|l|}{ Hot oil flow rate (L/min) } \\
\hline RD column & 2.8 & 2.1 & 3 & 2 & 2 & 3 \\
\hline Stripper & 2 & 1.5 & 0.3 & 0.2 & 2 & 2 \\
\hline Acetic acid conversion $(\%)$ & $\sim 100$ & $\sim 100$ & $\sim 100$ & $\sim 100$ & $\sim 100$ & $\sim 100$ \\
\hline$X_{\mathrm{B}, \mathrm{EtAc}}(\mathrm{mf})$ & 0.4056 & 0.9723 & 0.9225 & 0.9132 & 0.996 & 0.9995 \\
\hline
\end{tabular}

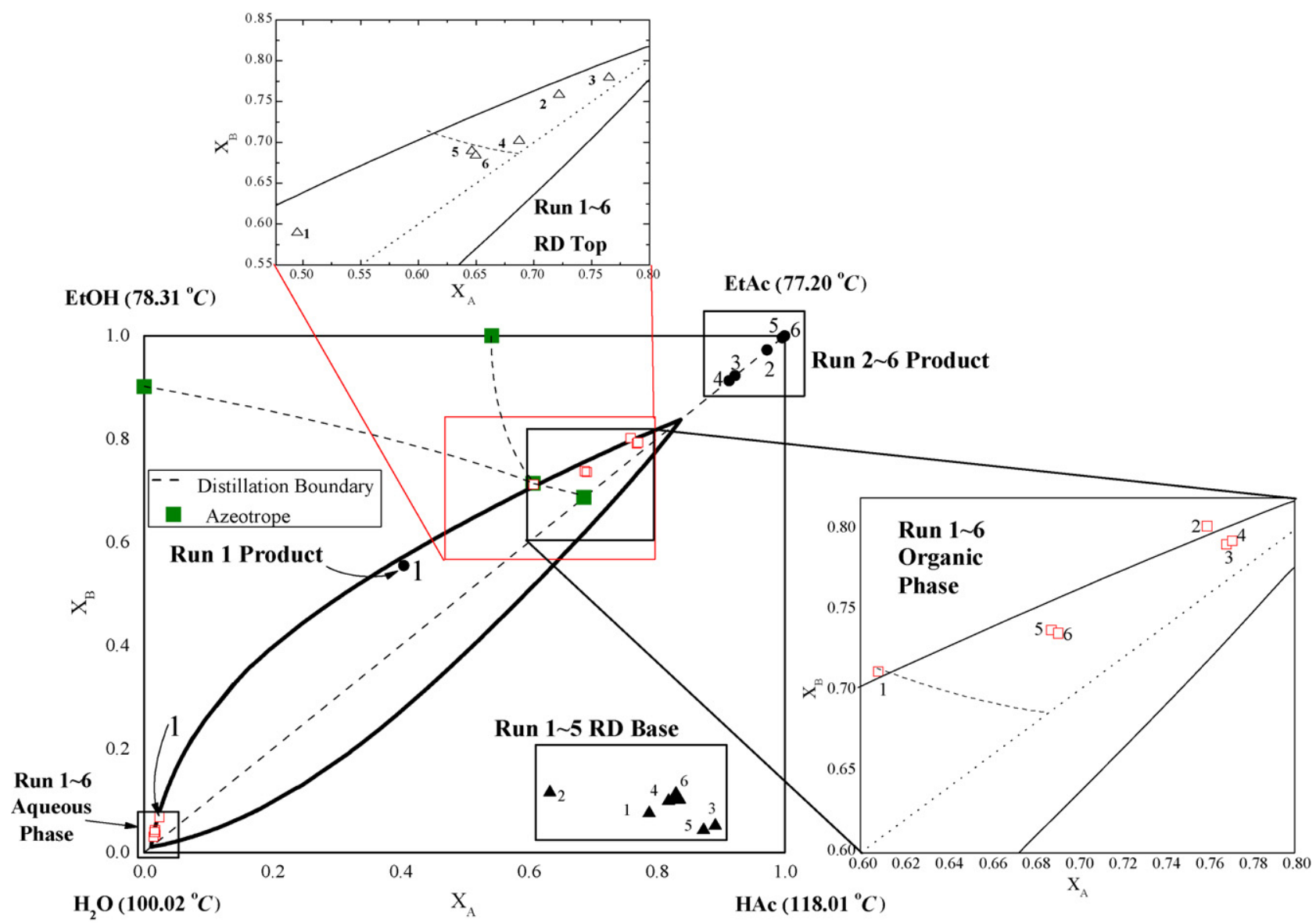

Fig. 10. Composition (aqueous, organic, RD base, stripper bottoms) profiles in quaternary composition space for Run \#1-6. 


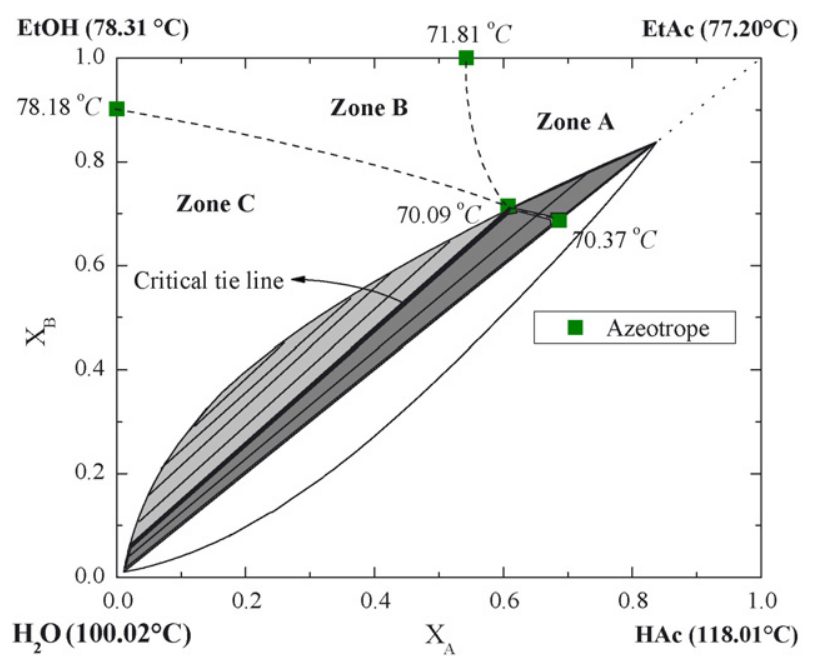

Fig. 11. The distillation boundaries and critical tie lines for achieving highpurity product (falling into zone A).

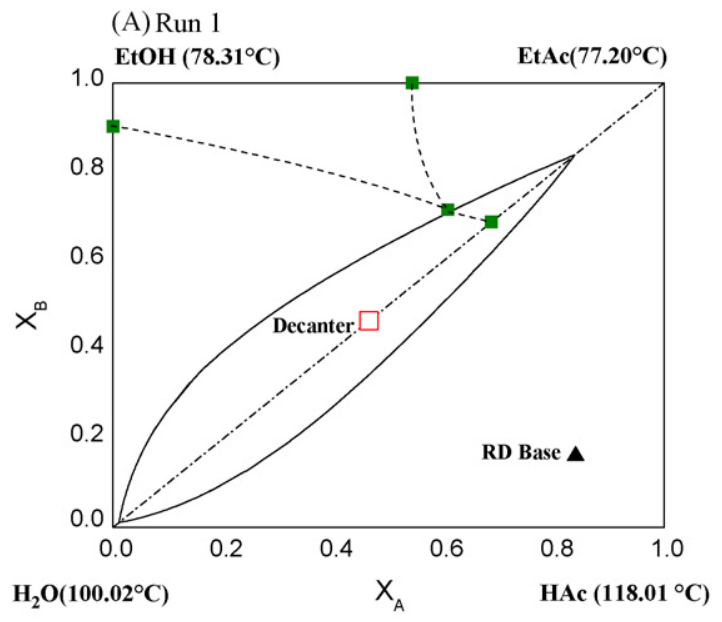

(B) Run 5

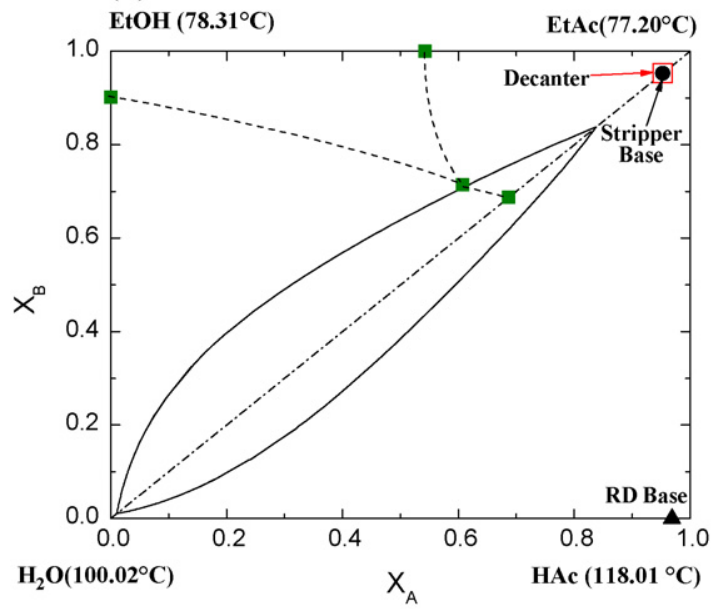

\subsection{Experimental results}

The effects of initial charges on starting up the columns are investigated, first. Six runs with different initial charges and operating conditions were tried on the plant. Table 3 summarizes the feed conditions, initial holdup charges, and operating conditions in each run. It is clear that, except for the first run (Run \#1), high-purity acetate can be produced from this pilotscale type-II process. During the first $4 \mathrm{~h}$ in a typical start-up run, the evolutions of tray temperatures in the RD and the stripper are shown in Fig. 8. According to the start-up procedure, the duration is divided into four distinct time zones (e.g. Fig. 8A, S1-S4 for the RD column, Fig. 8B, S5-S8 for the stripper). Fig. 8 shows the temperature responses in the RD column and the stripper of one typical run (e.g. Run 5). It shows that in the first hour, the temperatures front propagated toward the top of the $\mathrm{RD}$ column and the development of the temperature front in the stripper lags behind. This is because the stripper was heated up in a later stage. When reflux flow from the stripper starts returning to the RD column, tray temperature oscillation was observed, especially for those close to the column top. Similarly, the feed-
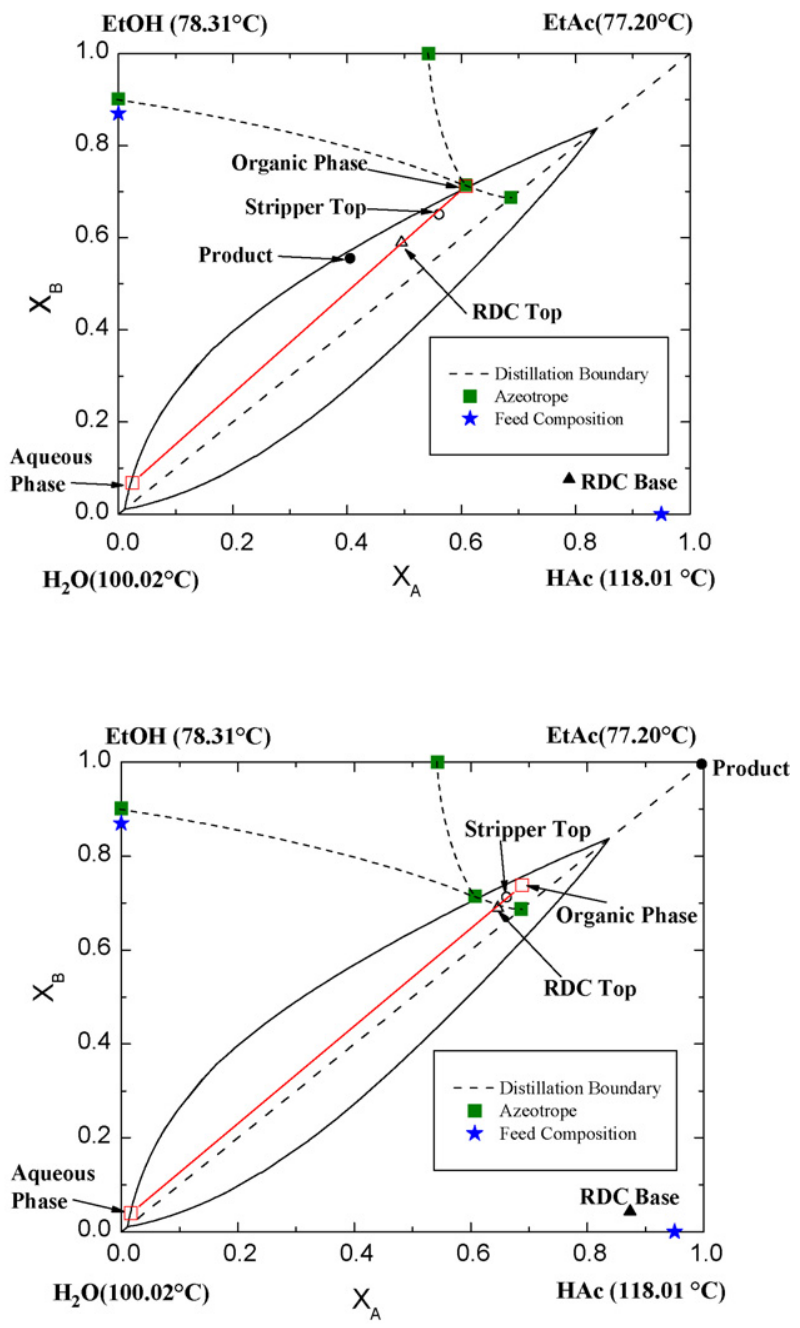

Fig. 12. Initial holdup composition (left) and column top composition, aqueous and organic compositions in the decanter and product composition (right) for: (A) Run \#1 and (B) Run \#5. 

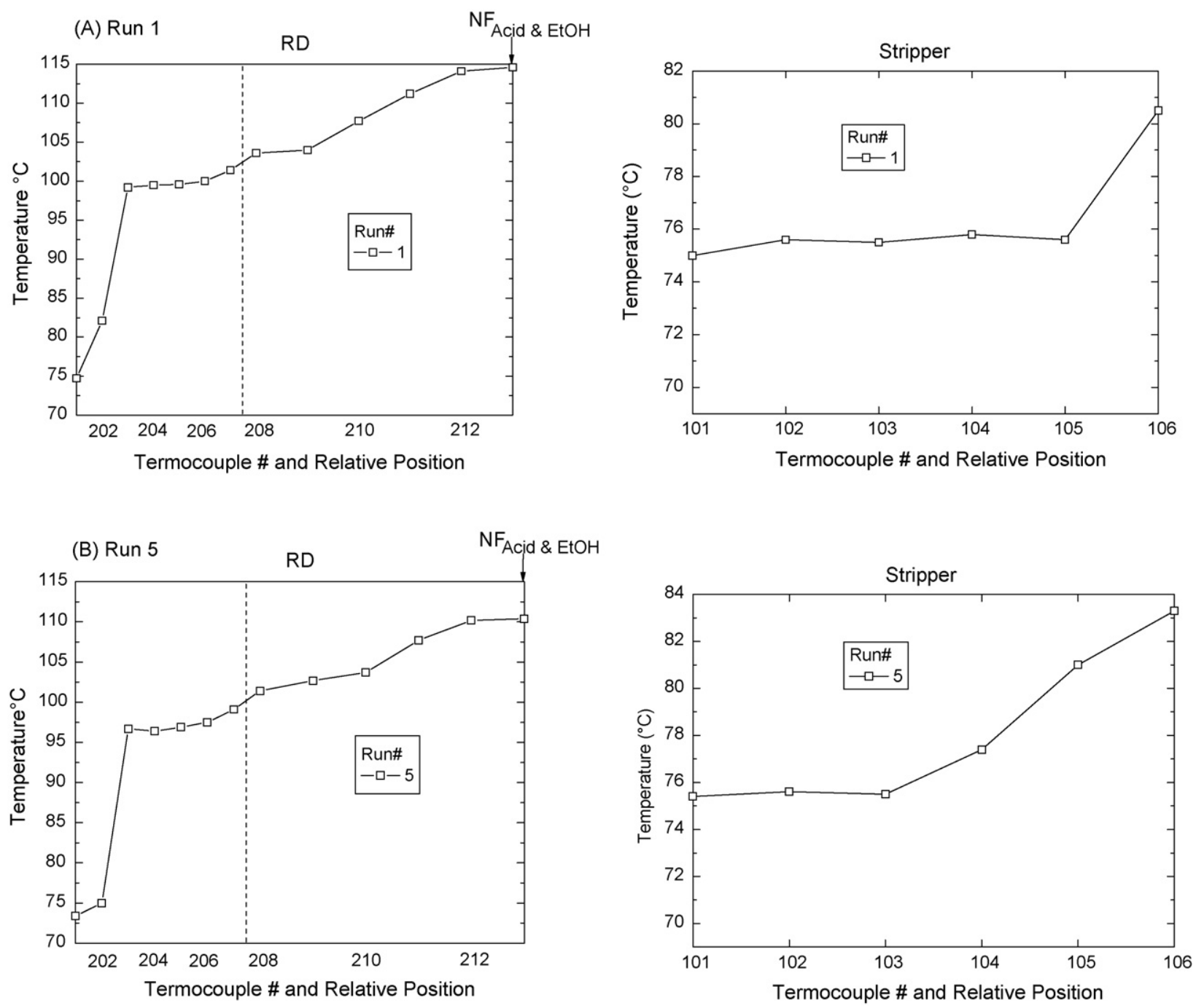

Fig. 13. Temperature profiles of RD column (left) and stripper (right) for: (A) Run \#1 and (B) Run \#5.

ing of the organic product into the stripper also leads stripper temperature to oscillate at a lower frequency. However, the RD tray temperatures stabilized almost $2 \mathrm{~h}$ after the start-up. Fig. 10 shows the steady-state composition (aqueous, organic, RD column base, stripper base) profiles in the quaternary composition space for all six runs. From this figure, Runs 2-6 have high purity of acetate, but Run 1 has much lower than expected. As one can see, in Runs $2-4$, the top compositions in the RD column all fall inside the zone A of Fig. 11, which contains almost pure acetate (see zone A of Fig. 11) in the same distillation region. The RD top composition of Runs 5 and 6, after mixing with the condensed overhead vapor from the stripper, cross the boundary as shown by the organic phase composition. That means the organic feed to and the product from the stripper of Runs 2-6 are in the same distillation region. On the other hand, Run 1 has an organic phase composition in zone $\mathrm{C}$, which is different from those of Runs 2-6 and is far off the boundary line connecting the $\mathrm{EtOH}-\mathrm{H}_{2} \mathrm{O}$ and $\mathrm{EtOH}-\mathrm{Et} A \mathrm{Ac}-\mathrm{H}_{2} \mathrm{O}$ azetropes. A likely scenario is that despite having achieving certain degree of LLE resulting from the initial charge to the decanter, the overall organic phase composition did not reach zone A. With this organic phase to the stripper for further purification, a high-purity acetate has never been obtained. In other words, the distillation boundary hinders the separation in the stripper to reach a higher purity for EtAc. Fig. 12 shows the transformed liquid and vapor compositions of either the initial holdup (Fig. 12A (left) and Fig. 12B (left)) or of the steady-states (Fig. 12A (right) and Fig. 12B (right)) of Runs 1 and 5. Notice that the coordinates are: $X_{\mathrm{A}}=X_{\mathrm{HAc}}+X_{\text {Acetate }}$, and $X_{\mathrm{B}}=X_{\text {Alcohol }}+X_{\text {Acetate }}$. It then becomes clear that the initial charge (i.e., composition) to the decanter is critical for an efficient start-up. Fig. 12A (left) indicates that Run 1 has an initial composition in zone $\mathrm{C}$ of Fig. 11, while compositions of decanter in Runs 2-6 are all in zone A of Fig. 11. The temperature profiles of RD and stripper in Run 1 and Run 5 are given in Fig. 13. Different temperature profiles in the stripper were observed, performing separation in different distillation regions, as shown in Fig. 13.

\subsection{Effect of initial holdup charges on the start-up}

As mentioned earlier, initial charges to the RD column base, decanter, and stripper base play an important role for a success- 
ful start-up. Fig. 12 shows the compositions of initial column holdup for Run 1 and Run 5, respectively. Table 3 shows that the initial charge to the RD bottom base is almost irrelevant to the success of a start-up, as long as they are reactants. However, in order to facilitate the start-up, feeding pure acid to the RD column base is preferable. Actually, this reveals a simple rule for initial charges: make the holdup composition close to the final steady-state value. Fig. 12A (left) and Fig. 12B (left) show that Run 1 differs from Run 5 in the initial composition in the decanter and in the base of the stripper. In Run 1, the decanter is charged with equal volume of acetate and water. This initial composition locates in the two-liquid-phase region on the water-rich side while not having any holdup in the bottoms of the stripper (Fig. 12A (left)). Without any acetate in the base of the stripper, at the very beginning, the stripper is performing separation in the wrong side of the distillation region (zone $\mathrm{C}$ in Fig. 11). This certainly will not help in concentrating acetate. In the start-up period of Run 1, the top product from the RD column does not have a true LLE. More importantly, it falls into zone $\mathrm{C}$ in Fig. 11. Once in zone $\mathrm{C}$, it never traverses the distillation boundary to zone A and high-purity acetate cannot be obtained. The product composition in Fig. 12A (right) clearly indicates that high-purity acetate cannot be obtained. In contrast to Run 1, Runs 2-6 have their RD top temperatures ranging from 72 to $75^{\circ} \mathrm{C}$ and organic phase compositions located in the right-hand side (or near) of the boundary. Thus, after condensation, the organic phase has its composition cross over the boundary into zone A of Fig. 11. In order to prevent from falling into incorrect distillation boundary, it is advisable to place acetate in the base of stripper.

\subsection{Product purity}

Form the successful Runs 2-6, Table 3 indicates that the process is rather tolerant to the reflux flow rate variation (varying from 80 to 125). Physically, an increase in the reflux ratio implies recycling more overhead organics back to the reactive zone of the RD column for better conversion. However, the column is designed for the experimental feed to have almost $100 \%$ conversion. Therefore, negligible amount of acid is left in the organic phase. As long as the organic phase composition falls into the correct distillation boundary (Fig. 10, right side), high-purity acetate can be expected. The purity level, however, depends on the degree of separation in the stripper, which, to a degree, proportional to the heat input to the stripper as shown in Table 3.

\subsection{Simulation versus experimental results}

Aspen Plus is used to simulate one experimental run with corresponding operational conditions. Among the five successful runs, Run 6 is the last experiment that we believe is more mature with the start-up operation. For this reason, the results from Run 6 are used to compare with those from simulation. Kinetics parameters using Amberlyst 35 are shown in Table 4. With the kinetics model, simulation is conducted by providing the following:
Table 4

Kinetic equations for EtAc System

\begin{tabular}{ll}
\hline System & EtAc \\
Kinetic model (catalyst) & Pseudo-homogeneous model (Amberlyst 35 \\
& wet), $r=m_{\mathrm{cat}}\left(k_{1} C_{\mathrm{HAc}} C_{\mathrm{EtOH}}-k_{-1} C_{\mathrm{EtAc}} C_{\mathrm{H}_{2} \mathrm{O}}\right)$, \\
& $k_{1}=1.24 \times 10^{9} \exp (-6105.6 / T)$, and \\
& $k_{-1}=1.34 \times 10^{8} \exp (-5692.1 / T)$ \\
$k_{1}(T=363 \mathrm{~K})$ & $61.47\left(\mathrm{~cm}^{6} \mathrm{~mol}^{-1} \mathrm{~g}^{-1} \mathrm{~min}^{-1}\right)$ \\
$K_{\mathrm{eq}}(T=363 \mathrm{~K})$ & 2.96 \\
\hline
\end{tabular}

$T(\mathrm{~K}), r(\mathrm{~mol} / \mathrm{min}), m_{\text {cat }}\left(\mathrm{g}_{\mathrm{cat}}\right), C_{i}$ (mole concentration).

(1) The number of theoretical trays in the rectifying section of the RD column, and, the number of theoretical trays in the stripper.

(2) The catalyst weight in the column base and in the reactive trays.

(3) All other operational conditions in one run.

During the simulation, efficiencies of the separation trays (i.e., rectifying section in the RD column and the stripper) are adjusted until the temperature profile from simulation fit the experimental one best.

Table 5 summarizes the setting of parameters used in simulation with Aspen Plus. The comparisons of the compositions thus obtained are given in Table 6. With the given conditions, simulation results predict high-purity products. Fig. 14 shows both the temperature profiles from simulation and from experiment.

Table 5

Settings in Aspen Plus simulation

\begin{tabular}{|c|c|c|}
\hline \multirow[t]{2}{*}{ Simulation } & \multicolumn{2}{|l|}{ EtAc } \\
\hline & RD column & Stripper \\
\hline VLE model & Tang et al. [1] & Tang et al. [1] \\
\hline Catalyst & Amerlyst 35 wet & - \\
\hline Kinetics model & Table 6 & - \\
\hline No. of trays in the stripper $\left(N_{\mathrm{s}}\right)$ & - & 10 \\
\hline No. of trays in reactive section $\left(N_{\mathrm{rxn}}\right)$ & 11 & - \\
\hline No. of trays in rectifying section $\left(N_{\mathrm{r}}\right)$ & 10 & - \\
\hline Reactive tray & $0-10$ & - \\
\hline Acetic acid feed tray & 0 (column base) & \\
\hline Alcohol feed tray & 0 (column base) & \\
\hline \multicolumn{3}{|l|}{ Tray efficiency } \\
\hline Rectifying section $\left(\eta_{\mathrm{r}}\right)$ & 0.9 & - \\
\hline Stripper trays $\left(\eta_{\mathrm{s}}\right)$ & - & 0.9 \\
\hline \multicolumn{3}{|l|}{ Feeds } \\
\hline$X_{\text {acid }}(\mathrm{mf})$ & 0.9675 & \\
\hline$X_{\mathrm{EtOH}}(\mathrm{mf})$ & 0.8698 & \\
\hline$F_{\text {acid }}(\mathrm{mol} / \mathrm{min})$ & 0.2858 & \\
\hline$F_{\mathrm{EtOH}}(\mathrm{mol} / \mathrm{min})$ & 0.3067 & \\
\hline Molar ratio $(\mathrm{Acid} / \mathrm{EtOH})$ & 0.985 & \\
\hline \multicolumn{3}{|l|}{ Operating variables } \\
\hline Reflux ratio & 1.07 & \\
\hline Reboiler duty $(\mathrm{kW})$ & 1.508 & 1 \\
\hline Column diameter (m) & 0.05 & 0.05 \\
\hline Decanter temperature $\left({ }^{\circ} \mathrm{C}\right)$ & 20 & \\
\hline \multicolumn{3}{|l|}{ Catalyst weight (g) } \\
\hline Reactive tray & 88 & - \\
\hline RD bottom & 880 & - \\
\hline
\end{tabular}


Table 6

Compositions from Aspen Plus simulation and experiment (Run 6)

\begin{tabular}{|c|c|c|c|c|c|c|c|c|c|c|c|c|}
\hline \multirow[t]{2}{*}{ Mole fraction } & \multicolumn{2}{|l|}{$\mathrm{RD}$ top } & \multicolumn{2}{|c|}{ RD bottom } & \multicolumn{2}{|c|}{ Organic phase } & \multicolumn{2}{|c|}{ Aqueous phase } & \multicolumn{2}{|c|}{ Stripper top } & \multicolumn{2}{|c|}{ Stripper bottoms } \\
\hline & Exp & Sim & Exp & Sim & Exp & Sim & Exp & Sim & Exp & Sim & Exp & Sim \\
\hline HAc & 0.0000 & 0.0000 & 0.7246 & 0.8710 & 0.0000 & 0.0000 & 0.0000 & 0.0000 & 0.0000 & 0.0000 & 0.0000 & 0.0000 \\
\hline EtAc & 0.6497 & 0.6607 & 0.1057 & 0.0395 & 0.6910 & 0.7285 & 0.0171 & 0.0158 & 0.6804 & 0.6796 & 0.9995 & 0.9996 \\
\hline Water & 0.3161 & 0.2899 & 0.1697 & 0.0860 & 0.2641 & 0.2114 & 0.9564 & 0.9588 & 0.2832 & 0.2503 & 0.0005 & 0.0004 \\
\hline
\end{tabular}

Although this experimental run gives high purity of EtAc, some deviations between the simulation and experimental results are observed.

The experiment shows that ethanol is almost used up in the RD column so that the ethanol compositions at different parts of the system (e.g. top and bottom of RD column, organic phase, and stripper top, etc.) are very small. As a result, some small
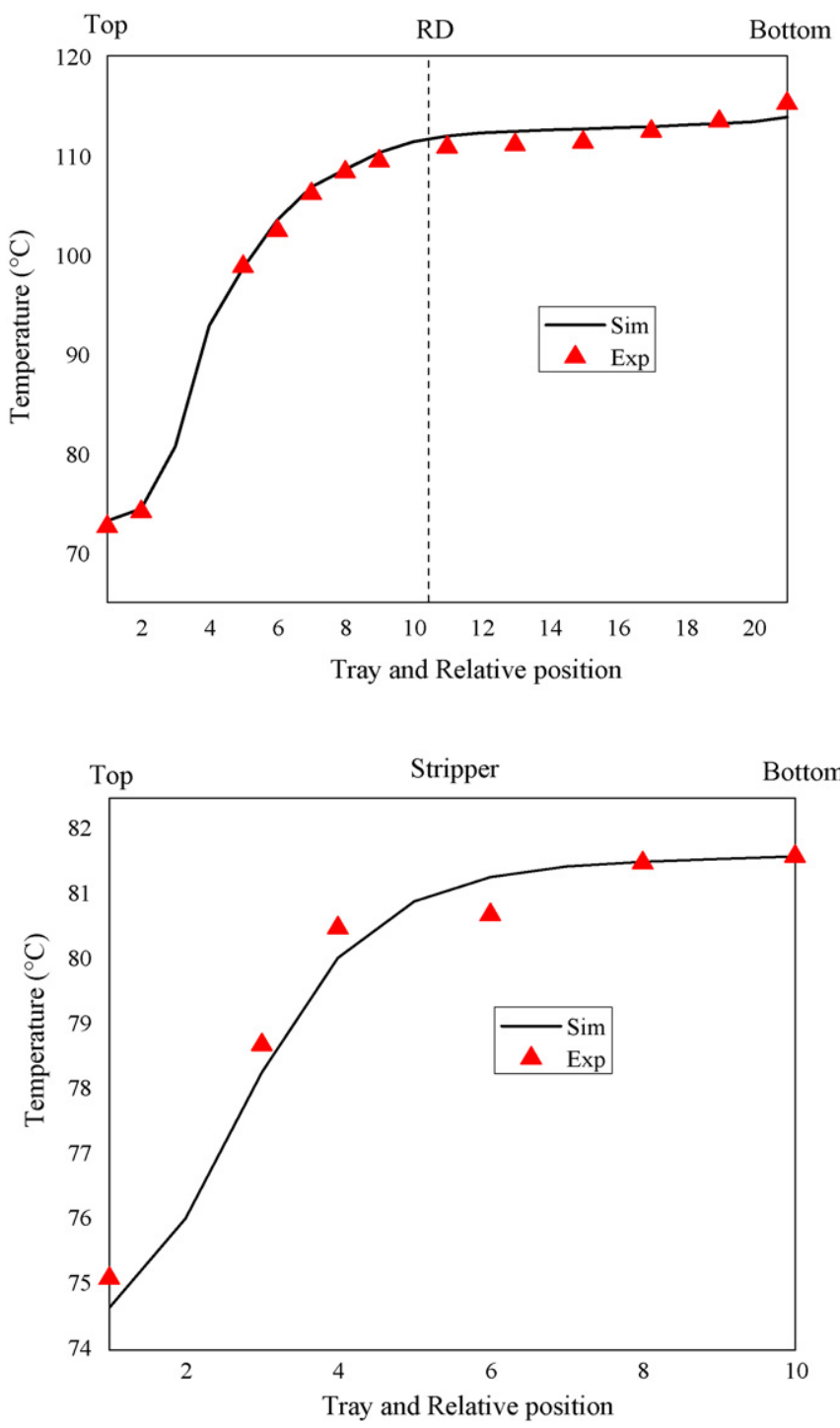

Fig. 14. Temperature profiles of RD column (top) and stripper (bottom) from Aspen Plus simulation (solid line) and experiment (Run \#6 in triangle). errors in sampling or measurement may cause large percentages of error under this circumstance. Because the organic phase and aqueous phase in the decanter may not settle well during the experiment, the compositions of HAc and water in these two phases may also subject to errors. There are still some other factors that may result in composition errors. For example, the efficiency of Jet Co-flow Packing Trays for reaction section is, in fact, unknown.

Despite some deviations of compositions from those of simulation, the experimental results validate the design concept. That is: if the top vapor composition of RD column falls in the feasible zone, the stripper with proper design will be capable of producing high-purty EtAc.

\section{Conclusion}

This paper presents an experimental realization of a conceptual type-II RD process for the production of ethyl acetate [1]. This type-II RD process consists of two columns, one reactive distillation column and a stripper, with recycle. In this work, a pilot plant is setup for the production of high-purity EtAc from ethanol (below azeotropic composition with water as impurity) and acetic acid (industrial grade) feeds. Six experimental runs with different initial charges (holdups in the column bases and decanter) and different operating conditions (e.g. heat input and reflux ratio) are shown. The results show that, initial holdup composition plays a critical role for a successful start-up. Moreover, high-purity acetate (up to $99.5 \mathrm{wt} \%$, or $99 \mathrm{~mol} \%$ ), indeed, can be obtained using the type-II flowsheet.

\section{Acknowledgment}

This work is supported by the Ministry of Economic Affairs of Taiwan under the grant 95-EC-17-A-09-S1-019.

\section{References}

[1] Y.T. Tang, Y.W. Chen, H.P. Huang, C.C. Yu, S.B. Huang, M.J. Lee, Design of reactive distillations for acetic acid esterification with different alcohols, AIChE J. 51 (2005) 1683-1699.

[2] D.B. Keyes, Esterification processes and equipment, Ind. Eng. Chem. 24 (1932) 1096-1103.

[3] K.C. Wu, C.T. Lin, US Patent 5,998,658 (1999).

[4] E.Y. Kenig, H. Bäder, A. Górak, B. Beßling, T. Adrian, H. Schoenmakers, Investigation of ethyl acetate reactive distillation process, Chem. Eng. Sci. 56 (2001) 6185-6193. 
[5] M. Klöker, E.Y. Kenig, A. Górak, A.P. Markusse, G. Kwant, P. Moritz, Investigation of different column configurations for the ethyl acetate synthesis via reactive distillation, Chem. Eng. Process 43 (2004) 791-801.

[6] F. Reepmeyer, J.U. Repke, G. Wozny, Time optimal start-up strategies for reactive distillation columns, Chem. Eng. Sci. 59 (2004) 4339-4347.

[7] K. Kolena, J. Lederer, P. Morávek, J. Hanika, Q. Smejkal, D. Skála, US Patent 6,693,213 (2004).
[8] S.B. Hung, Y.T. Tang, Y.W. Chen, I.K. Lai, W.J. Hung, H.P. Huang, M.J. Lee, C.C. Yu, Control of different reactive distillation configurations for acetic acid esterification, AIChE J. 52 (2006) 1423-1440.

[9] I.K. Lai, S.B. Hung, W.J. Hung, C.C. Yu, M.J. Lee, H.P. Huang, Design and control of reactive distillation for ethyl and isopropyl acetates production with azeotropic feeds, Chem. Eng. Sci. 62 (2007) 878-898. 